\title{
Long-run validity of purchasing power parity and rank tests for cointegration for Central Asian countries
}

\author{
Venus Khim-Sen Liew ${ }^{\mathrm{a}, \mathrm{b}, *}$, Ricky Chee-Jiun Chia ${ }^{\mathrm{b}}$ \\ and Tai-Hu Ling ${ }^{\mathrm{b}}$ \\ ${ }^{\mathrm{a}}$ Faculty of Economics and Business, Department of Economics, Universiti \\ Malaysia Sarawak, 94300 Kota Samarahan, Sarawak, Malaysia \\ ${ }^{\mathrm{b}}$ Labuan School of International Business and Finance, Universiti Malaysia \\ Sabah, Jalan Sungai Pagar, 87000 Labuan, Malaysia
}

This study finds that Purchasing Power Parity (PPP) holds in the long-run for Azerbaijan, Kazakhstan and Kyrgyzstan, based on Breitung's (2001) rank tests for cointegration. Results from further analysis indicates that nominal exchange rates and relative prices are nonlinearly interrelated. Trade barriers, transportation costs and government intervention in the pricing system in these countries may have resulted in the establishment of the above-mentioned nonlinear relationship.

\section{Introduction}

The existence of long-run relationship between nominal exchange rate and relative price, as postulated by the Purchasing Power Parity (PPP) hypothesis, has been extensively investigated over the past three decades. The attractiveness of testing this hypothesis is that it may provide useful guidelines for economic agents. For instance, the validity of PPP hypothesis reflects well-integrated goods markets and henceforth suggesting the nonexistence of arbitraging opportunity between the domestic and foreign countries. Besides, the validity of PPP enables the prediction of long-run exchange rate movement via PPP model or its extended monetary models.

Previously, most studies are conducted using data from a substantially large range of developed and developing countries; see Taylor (2003), Taylor and Taylor (2004) and Taylor (2006). Recently, Doğanlar (2006) for the first time in the literature, contributes to the discussion by examining the various versions of PPP formulations for Central Asian countries (Azerbaijan, Kazakhstan and Kyrgyztan), which have undergone transitional economy system and thereby trade structure since the broke up of the Soviet Union in 1991. Based on various well-accepted methodologies including the Engle and Granger's (1987) test, Johansen's (1988, 1991) multivariate cointegration test, Fully Modified Ordinary Least Squares (FOLS) procedure of Phillips and Hansen (1990), as well as the more recently available Autoregressive Distributed Lag (ARDL) technique of Pesaran and Shin (1999), the author was unable to reject the null hypothesis of no cointegration (implying no long-run

*Corresponding author. E-mail: venusliew@yahoo.com

\footnotetext{
Applied Economics Letters ISSN 1350-4851 print/ISSN 1466-4291 online (C) 2010 Taylor \& Francis 